\title{
Doença mão-pé-boca no atendimento odontopediátrico
}

\author{
Hand-foot-mouth disease in pediatric care \\ Enfermedad de manos, pies y boca en atendimiento odontológico de niños \\ Priscila Higa NAKAO \\ Dalva Pereira TERRA \\ Mario Eduardo BALDO \\ Ellen Cristina GAETTI JARDIM \\ Faculdade de Odontologia da Universidade Federal de Mato Grosso do Sul (Faodo-UFMS)79070-900 Campo Grande-MS, Brasil
}

\section{Resumo}

A doença mão-pé-boca é uma infecção viral, normalmente benigna que afeta comumente crianças até 10 anos, causada pelos enterovírus humano. O propósito deste estudo foi revisar os aspectos da doença que se faz presente nos dias atuais abordando a etiologia, epidemiologia, surtos, sintomatologia e comorbidades, diagnóstico, prevenção e tratamento. Foram selecionadas publicações em periódicos referenciados nas fontes de dados do Google Acadêmico, Pubmed e Periódicos Capes com as palavras chaves relacionadas ao tema desse trabalho como doença mão-pé-boca e crianças, sendo selecionados artigos produzidos até 2017. Apesar de diagnóstico clínico aparentemente simples, a doença pode ser confundida com outras enfermidades por suas características semelhantes, que podem induzir o colega odontólogo ao equívoco de diagnóstico.

Descritores: Doença de Mão, Pé e Boca; Diagnóstico, Odontopediatria.

\section{Abstract}

Hand Foot and Mouth disease is a viral infection, usually benign that commonly affects children up to 10 years old, caused by human enterovirus. The purpose of this study was to review aspects of the disease that is present in today regarding the etiology, epidemiology, outbreaks, symptoms and comorbidities, diagnosis, prevention and treatment. Were selected publications in journals referenced in the sources of Google Scholar, Pubmed and Periódicos Capes data with the key words related to the theme of this work as hand, foot and mouth disease and children, selecting articles produced until 2017. Despite a seemingly simple clinical diagnosis, the disease can be confused with other diseases because of their similar characteristics, which may induce a dentist to the wrong diagnostic.

Descriptors: Hand, Foot and Mouth Disease; Diagnosis; Pediatric, Dentistry.

\section{Resumen}

La enfermedad de la mano a la boca es una infección viral normalmente benigna que comúnmente afecta a niños menores de 10 años causada por enterovirus humanos. El propósito de este estudio fue revisar los aspectos actuales de la enfermedad, abordando la etiología, epidemiología, brotes, sintomatología y comorbilidades, diagnóstico, prevención y tratamiento. Seleccionamos publicaciones en revistas a las que se hace referencia en Google Scholar, Pubmed y Capes Periodicals con las palabras clave relacionadas con el tema de este trabajo como enfermedad de manos, pies, boca y niños, y artículos producidos hasta 2017. A pesar del diagnóstico clínico aparentemente simple, la enfermedad puede confundirse con otras enfermedades debido a sus características similares, que pueden inducir al dentista colega a un diagnóstico erróneo.

Descriptores: Enfermedad de Boca, Mano y Pie; Diagnóstico; Odontología Pediátrica.

\section{INTRODUÇÃO}

A doença mão-pé-boca é uma doença considerada benigna ${ }^{1}$, altamente contagiosa, que acomete na maioria das vezes crianças menores de 10 $\operatorname{anos}^{2-4}$ podendo ocorrer em indivíduos adultos também $^{5,6}$. Foi descrito primeiramente em 1958 por Robinson et $\mathrm{al}^{7}$, como presença de febre, lesões ulcerativas da face e boca, mácula e após, bolhas e úlceras, no qual o vírus Coxsackie do Grupo A foi encontrado em $71 \%$ dos pacientes. E, em Birmigham, Alsop, 1960 et $\mathrm{al}^{8}$, sugeriram o nome de "hand-footand-mouth-disease".

É uma patologia viral, com transmissão, pela via respiratória, feco-oral e por contato com o líquido das vesículas durante a fase ativa da doença, o período de incubação é de aproximadamente de 3 a 6 dias e os seres humanos são os únicos hospedeiros ${ }^{4,9}$ A doença pode ser causada por vários tipos de enterovírus e os Coxsackie A 16 (CA16) e o enterovírus 71 (EV71) são os comumente envolvidos, porém outros vírus podem provocar essa enfermidade $^{4,5}$. O diagnóstico usualmente é clínico, com febre e erupções maculo papular ou vesicular nas palmas das mãos e nas plantas dos pés, às vezes associadas às úlceras bucais. As lesões cutâneas podem ser encontradas também nas pernas, face, nádegas e tronco. A cultura viral é considerada a forma mais eficiente para a identificação das cepas, porém o resultado pode demorar uma semana, sendo realizado somente nos casos suspeitos de severidade ou nas pesquisas públicas de saúde em surtos da doença ${ }^{10}$.

O quadro clínico normalmente se inicia com febre, falta de apetite, mal-estar, manchas, as quais posteriormente se tornam úlceras dolorosas na boca. A língua, gengiva, úvula, mucosa oral e palato, são os locais mais acometidos, a regressão das lesões bucais ocorre entre 5 a 7 dias. As erupções cutâneas surgem em 75\% dos pacientes na forma de pápulas e vesículas, na maioria das vezes nas palmas das mãos e nas plantas dos pés, podendo aparecer nos joelhos, cotovelos, nádegas. As manchas geralmente são indolores, sem prurido, porém podem evoluir para bolhas dolorosas, as quais desaparecem por volta de 7 a $10 \operatorname{dias}^{3,9}$, o aparecimento da doença normalmente ocorre na primavera até o outono ${ }^{10}$.

O presente estudo é uma revisão bibliográfica sobre os aspectos dessa doença viral que se faz presente nos dias atuais descrevendo sobre a etiologia, epidemiologia, surtos, sintomatologia e comorbidades, diagnóstico, prevenção e tratamento da entidade clínica conhecida como doença mão-péboca, que apesar de descoberta em 1958, ainda apresenta surtos pelo mundo e com sintomas semelhantes às outras doenças, as quais podem induzir o colega odontólogo ao equívoco de diagnóstico. 


\section{MATERIAL E MÉTODO}

Foram selecionadas publicações em periódicos referenciados nas fontes de dados do Google acadêmico, Pubmed e Periódicos Capes com as palavras chaves relacionadas ao tema desse trabalho como doença mão-pé-boca e crianças, sendo selecionados artigos produzidos até 2017 considerados mais relevantes tanto na abordagem do tema discutido quanto na abrangência epidemiológica dos mesmos. Os critérios de exclusão foram artigos que não foram abrangentes ou que chegaram a dados inconclusivos e de baixa relevância científica.

\section{RESULTADOS}

\section{- Etiologia}

A doença da mão-pé-boca é causada pela família Picornaviridae, sendo os mais comuns os Coxsakievirus A16 e o Enterovirus $71^{4}$. Outos vírus que podem estar envolvidos no aparecimento da doença são os Coxsackie A5, A9, A10, ecovirus $9^{12}$. Repass et al $^{10}$ em 2014 apontaram, juntamente com os Coxsackie A16 e o EV71, o Coxsackie A6 como agente causador da doença, e muitas outras cepas de coxsackievirus, incluindo A5, A7, A9, A10, B2 e B5, sendo o Coxsackievirus A16 o principal agente etiológico e o enterovírus 71 frequentemente associado às complicações neurológicas e cardiopulmonares, assim como Xing et $\mathrm{al}^{13}$ que também constataram que nos casos mais severos a cepa EV71 era o predominante e Fatahzadeh em $2017^{3}$, relatou que os surtos graves de doença envolvem frequentemente coxsakievirus A6.

Wu et al. ${ }^{14} \mathrm{em} 2010$ fizeram um estudo para identificar a circulação dos vírus causadores da doença em um grande surto na Singapura ocorrido em 2008. Foram coletados esfregaços da garganta, nariz, retal, saliva, urina e exame de sangue. As 43 crianças com suspeita de serem portadores da doença, foram submetida a exames e conseguiram realizar o isolamento dos vírus, identificando-os pela reação em cadeia da polimerase reversa (RT-PCR) e sequenciamento. Os enterovírus foram identificados em $66,7 \%$ das amostras e destas, 21,6\% foram positivos para o EV71 e 45,1\% positivos para outros vírus não-EV71, como os Coxsackie A4, A6, A10 e A16.

Em 2017, Wang et al. $^{15}$ descreveram as características epidemiológicas da doença, na província de Shandong, na China de 2009 a 2016, com 48.133 casos confirmados em laboratório da doença. A maior parte era crianças menores de 5 anos (90,5\%), com a média de 2,4 anos, do gênero masculino e destes, 75 vieram à óbito. A prevalência do enterovírus A71 foi de 67\% em 2009, 50\% em 2011 e 39\% em 2014; já do Coxsackie vírus CA16 foi de 37\% em 2010, 45\% em 2012 e 53\% em 2016.

Estudos locais que avaliaram a epidemia e a etiologia da doença mão-pé-boca em Xiamen, China de entre
2008 e 2015, mencionam que os enterovírus causaram 27.227 casos da doença, sendo que 99 eram severos gerando 6 óbitos notificados. Foram analisados 5866 casos, encontraram 4290 positivos para o enterovirus humano. Os patógenos mais comuns descobertos foram os enterovirus 71, coxsackie A16, A6 e A10, sendo que desde 2013 o coxsackie A6 (CA6) vem substituindo o CA16 como um dos dois mais comuns genótipos. Os outros pertenciam à espécie $\mathrm{B}$, e o coxsackievirus B3 (CB3) representava a maior proporção. Nos casos severos, o EV71 foi responsável por $78,08 \%$ dos casos seguido por CA16, CA10 e outros e vale ressaltar que nenhum dos casos severos foi causado pelo CA6.

- Epidemiologia

Em 2014 Xing et al. ${ }^{13}$ realizaram um estudo epidemiológico na China com 267.942 casos confirmados da doença mão-pé-boca nos anos de 2008 a 2012. Dos 267.942 pacientes estudados, 2457 $(0,91 \%)$ evoluíram para o óbito. A prevalência da mortalidade foi maior em crianças entre 12 a 23 meses de idade. Concluíram que os indivíduos do gênero masculino, menores de 5 anos eram 1,6 vezes mais sujeitos a desenvolver a doença do que os do gênero feminino da mesma idade e que a doença tende a manifestar-se durante os meses mais quentes. Referem que fatores de risco para casos severos são a idade, crianças mais jovens são mais suscetíveis a apresentarem quadros clínicos mais sérios. Foi constatado que residir na área rural, pela maior dificuldade em ter acesso aos cuidados médicos, e infecção pelo EV71 também são fatores de risco para adquirirem quadros clínicos graves.

A doença mão-pé-boca manifesta-se em todo o mundo, sendo que os surtos geralmente ocorrem na primavera, verão e outono, em crianças abaixo dos 10 anos e sem predileção de gênero ${ }^{10}$. A Tabela 1 ilustra evolução cronológica dos surtos ocorridos no continente asiático e Estados Unidos entre 1998 a 2012.

Tabela 1: Evolução cronológica dos surtos da doença mão-pé-boca no continente asiático e Estados Unidos da América de 1998 a 2012

\begin{tabular}{l|c|c|c|}
\hline \multicolumn{1}{|c|}{ Local } & Ano & Número & Mortes \\
\hline Taiwan & 1998 & 1,5 milhão & 78 \\
\hline Linyi & 2007 & 1149 & 3 \\
\hline Fuyang & 2008 & 353 & 22 \\
\hline $\begin{array}{l}\text { China, Singapura, Vietnã, } \\
\text { Mongólia e Brunei }\end{array}$ & 2008 & 30000 & 50 \\
\hline China & 2009 & ${ }^{*} \mathrm{NE}$ & 35 \\
\hline Sul da China & 2010 & 70.000 & 600 \\
\hline EUA & $2011-2012$ & 63 & ${ }^{*} \mathrm{NE}$ \\
\hline
\end{tabular}

Chatproedprai et al. ${ }^{18}$ em 2010 fizeram um estudo com 48 casos da doença, com indivíduos com média de idades de 3 anos e predominantemente do sexo. Foram coletadas amostras das fezes, fluido vesicular e da garganta de onde procurou-se determinar o enterovírus e respectivo subtipo. $\mathrm{O}$ enterovírus 71 foi o agente etiológico predominante $(47,9 \%)$, as manifestações bucais foram as mais 
encontradas $(89,6 \%)$, seguidas pelas erupções nas mãos, pés, joelhos, nádegas e cotovelos sendo verificado quadro febril em 50\% dos pacientes examinados. Os autores sugerem que existe a necessidade da orientação profissional, parental e aos demais indivíduos que entram em contato com esses pacientes, afirmando que estes $\mathrm{s}$ deveriam elevar $\mathrm{o}$ nível de atenção em relação à doença, pois o EV71 pode causar complicações cerebrais, encefalite, edema pulmonar e até mesmo a morte.

Em revisão sistemática realizada na Ásia, sobre a epidemiologia da doença, Koh et al. ${ }^{20} \mathrm{em}$ 2016 evidenciaram resultados que estabelecem as áreas rurais como sendo de maior risco para contração da enfermidade, que a referida doença afeta ambos os gêneros, porém que os indivíduos do gênero masculino são mais propensos a desenvolverem sintomas e a propagarem a doença durante os surtos. Os autores especificam evidências sobre a existência de períodos de incubação ou latência.

\section{- Sintomatologia e comorbidades}

$\mathrm{Lam}^{22} 2010$ relata que a febre, linfadenopatia, presença de máculas, vesículas ovais dolorosas de 2 a $8 \mathrm{~mm}$ acinzentadas com halo avermelhado na palma das mãos e planta dos pés, mucosa bucal, palato duro e língua, foram os sinais e sintomas encontrados. Aproximadamente $3 / 4$ dos pacientes apresentarão vesículas e pápulas nas mãos e pés ${ }^{3}$.

Sarma $^{2}$ em 2013 caracterizou a doença pela presença de febre, surgimento de vesículas eritematosas, redondas ou ovais, normalmente na mão, pés, área perioral, joelhos, nádegas e na boca. $\mathrm{O}$ líquido da vesícula é inicialmente claro, mas rapidamente torna-se turvo imitando pústulas.

Segundo a Organização Mundial de Saúde ${ }^{23}$ os principais sintomas são a febre, falta de apetite, dor de garganta, mal-estar, úlceras bucais que precedem as erupções cutâneas na palma das mãos, nas solas dos pés e outras partes do corpo.

Ganga em $2017^{24}$ fez um estudo descritivo sobre o perfil clínico da doença mão-pé-boca em 21 crianças de outubro a novembro de 2015, destas, 15 eram do gênero masculino e 6 do gênero feminino. $O$ critério de inclusão foi a presença de lesões na pele com ou sem lesões bucais. Os pacientes foram submetidos a exame clínico, tratados e acompanhados. As lesões orais foram detectadas em 20 crianças, febre em 14 e infecções respiratórias em 6 casos. Os locais predominantes das lesões orais foram a mucosa bucal (20), tonsilas (17), lábios e língua (13) e úlceras sobre a língua (2). A Tabela 2 apresenta os locais de predileção das erupções cutâneas na doença mão-pé-boca, descritos na literatura desde 1999 até 2017. Outros achados clínicos encontrados foram vômito, anorexia e coceira. Todas as crianças com lesões orais tiveram dificuldade para comer e as mais novas salivaram excessivamente. Observaram que essas lesões da boca se curaram mais rápido que as da pele

Tabela 2: Locais de predileção das erupções cutâneas na doença mão-péboca, descritos na literatura desde 1999 até 2017

\begin{tabular}{|l|c|c|c|c|c|c|c|c|}
\hline $\begin{array}{l}\text { Chang et } \\
\text { al.25 }\end{array}$ & Mãos & Pés & Joelhos & Nádegas & Cotovelo & Pernas & Face & Tronco \\
\hline $\begin{array}{l}\text { Chatproedpri } \\
\text { et al.18 }\end{array}$ & $\mathrm{S}$ & $\mathrm{S}$ & $\mathrm{S}$ & $\mathrm{S}$ & $\mathrm{S}$ & & & \\
\hline Lam $^{22}$ & $\mathrm{~S}$ & $\mathrm{~S}$ & & $\mathrm{~S}$ & & & & \\
\hline Sarma $^{2}$ & $\mathrm{~S}$ & $\mathrm{~S}$ & $\mathrm{~S}$ & $\mathrm{~S}$ & & & & \\
\hline $\begin{array}{l}\text { Dantas et } \\
\text { al.17 }\end{array}$ & $\mathrm{S}$ & $\mathrm{S}$ & & & & & & \\
\hline $\begin{array}{l}\text { Cristovam } \\
\text { et al.9 }\end{array}$ & $\mathrm{S}$ & $\mathrm{S}$ & $\mathrm{S}$ & $\mathrm{S}$ & $\mathrm{S}$ & & & \\
\hline Xing et al. ${ }^{13}$ & $\mathrm{~S}$ & $\mathrm{~S}$ & & $\mathrm{~S}$ & & & & \\
\hline $\begin{array}{l}\text { Repass et } \\
\text { al.10 }\end{array}$ & $\mathrm{S}$ & $\mathrm{S}$ & & & & $\mathrm{S}$ & $\mathrm{S}$ & $\mathrm{S}$ \\
\hline $\begin{array}{l}\text { Kashyap e } \\
\text { Kashyap }^{11}\end{array}$ & $\mathrm{~S}$ & $\mathrm{~S}$ & $\mathrm{~S}$ & & & & & $\mathrm{~S}$ \\
\hline Fatahzade $^{3}$ & $\mathrm{~S}$ & $\mathrm{~S}$ & & & & & & \\
\hline
\end{tabular}

Fonte: Dados da Pesquisa

A doença mão-pé-boca pode causar desidratação, meningite asséptica, paralisia focal aguda, encefalite, linhas de Beau, onicomadese e também evoluir para problemas cardiopulmonares ${ }^{4}$.

Apesar de ser considerada uma doença benigna, pode demandar tratamento médico imediato pelas complicações no sistema nervoso central e pulmonares que podem ser fatais. Habitualmente o enterovirus 71 é o envolvido nas infecções mais graves $^{22,25}$. Em 2017, Pham et al. ${ }^{21}$ publicaram um estudo com 744 casos da doença, no Vietnã, descreveram as características clínicas associadas aos casos severos da doença. Os achados foram febre maior que $38,5^{\circ} \mathrm{C}(93,5 \%)$, bolhas $(99,1 \%)$, mioclonia $(58,5 \%)$ e úlceras na boca $(21,1 \%)$ sendo os sintomas como úlceras bucais, mioclonia e leucocitose, relacionados com os casos severos da doença.

Cabrol et al. ${ }^{26}$ em 2017 realizaram um estudo prospectivo do surto da doença no Camboja, com 122 pacientes de março a julho de 2014, 29 pacientes evoluíram sem complicações e 93 pacientes apresentaram quadro clínico com as formas graves da infecção. Confirmaram que o enterovirus A71 é um agente relevante da encefalite e os fatores de risco para a severidade da doença são o gênero, no caso o masculino, ausência de lesões na boca e pele, demora para internação hospitalar, febre alta ou prolongada e vômitos.

\section{- Diagnóstico diferencial}

A identificação da doença mão-pé-boca é realizada através de observações clínicas, porém quando há suspeita de severidade, o padrão ouro é a cultura do vírus. Uma das dificuldades do diagnóstico conclusivo é a demora no resultado, o qual pode levar uma semana ${ }^{10}$. O reconhecimento dessa enfermidade é clínico, baseado na idade, sintomas, tipo e localização das erupções e feridas ${ }^{1,22} \mathrm{O}$ diagnóstico definitivo é feito com identificação do vírus por PCR ou isolando o vírus em cultura. Esse exame prima pela identificação do tipo de enterovirus no fluido da vesícula, fluido cérebro espinhal, sangue, biópsia, no esfregaço da garganta ou nas fezes e a confirmação 
laboratorial se faz em casos de pesquisa, análise das cepas ou em casos atípicos da doença ${ }^{1,2,4,22}$.

Alterações na mucosa como aftas, herpangina e/ou gengivoestomatite herpética, varicela, eritema multiforme, herpes zoster bem como erupções de origem medicamentosa possuem certa similaridade com a sintomatologia da doença mão-pé-boca ${ }^{3,22}$. Segundo Fatahzadeh $^{3}$ em 2017, o diagnóstico diferencial da doença mão-pé-boca são gengivoestomatite herpética primária e o herpes zoster.

A gengivoestomatite herpética se manifesta geralmente em crianças de 1 a 5 anos, que teve contato com o vírus herpes tipo 1 pela primeira vez, produzindo febre, inchaço, inflamação e sangramento gengival, linfadenopatia cervical, vesículas e úlceras na boca e região perioral. A herpangina também ocorre em crianças pequenas, com sintomas de febre, mal estar e lesões orais principalmente no palato mole, úvula, parede posterior da faringe, tonsilas porém sem manifestações cutâneas, originando dor e exsudato de garganta, odinofagia, disfagia, ${ }^{3,10}$. A estomatite aftosa é caracterizada por úlceras maiores, dolorosas afetando os lábios, língua e mucosa bucal, normalmente ocorrendo em crianças e adolescentes. Já as lesões por varicela, envolvem uma área de pele maior, incluindo o couro cabeludo, sem as palmas das mãos e pés e criam crostas, enquanto as lesões da doença mão-pé-boca cessam pela reabsorção do líquido dentro da vesícula e no sarampo, os indivíduos apresentam tosse, coriza, conjuntivite e manchas de koplik na boca ${ }^{1,7}$.

\section{- Tratamento}

O tratamento é sintomático e preventivo ${ }^{10}$. Segundo Cepeda, 2016 ${ }^{6}$, o paciente deve ingerir muito líquido e nenhum enxaguante com anestésico deve ser usado para alívio da dor e evitar alimentos ácidos, apimentados e que demandem esforço mastigatório. Complicações neurológicas, encefalite, edema pulmonar e até a morte, podem ocorrer, comumente causadas pelo enterovirus $71^{18}$. É uma doença autolimitada com bom prognóstico. Nenhuma vacina ou medicamento específico para o tratamento das infecções por enterovírus estão disponíveis, sendo o tratamento de suporte e $^{2,27}$ e enxagüante anestésico para aliviar o desconforto; hidratação, alimentação líquida, pastosa e repouso são necessários ${ }^{3}$ usualmente a melhora ocorre em até 7 $\operatorname{dias}^{28}$. O tratamento se faz com analgésico, antipirético, anti-inflamatório e clorexidina para aliviar os sinais e sintomas. Os medicamentos para controle das dores e febre são paracetamol e ibuprofeno ${ }^{9}$. Segundo Repass et al. ${ }^{10}$, a doença não deve ser tratada com aciclovir e a imunoglobulina intravenosa também não tem indicação.

Wolf e Otto ${ }^{29}$, em 2015, publicaram um estudo comparativo, randomizado, controle-placebo e duplo cego sobre a eficácia e segurança do gel de lidocaína à $2 \%$ em 161 crianças de 6 meses a 8 anos com dor na cavidade bucal. $\mathrm{O}$ parâmetro da dor foi medido em uma escala com figuras de rosto de dor, que eram apontadas pelas crianças ou pelos pais, quando as mesmas não possuíam competência para distinguir as imagens. Os autores concluíram que o gel de lidocaína à $2 \%$ é um recurso aceitável, a curto prazo, para diminuir ou prevenir a dor na mucosa oral ou gengiva ocasionadas por mordida, aftas, doença da mão-pé-boca, entre outras.

\section{- Transmissão, prevenção e cuidados}

Os humanos são os únicos hospedeiros conhecidos do grupo enterovírus, a transmissão é através do contato com as fezes, fluidos respiratórios, entre os familiares, da mãe para a criança, nas escolas, creches, brinquedotecas, acampamentos, orfanatos e pelos funcionários de um hospital. $\mathrm{O}$ enterovírus pode sobreviver em superfícies, ser encontrados na água e esgoto e sobreviver em solo úmido por vários meses e nas fezes por até um mês ${ }^{1,9,15}$. Em 2016, Li et al. ${ }^{28}$ publicaram uma análise com 603 crianças com doença mão- pé-boca severa e 1036 crianças com a doença leve e demonstrou que o aleitamento materno por 6 a 12 meses ou mais reduziu significantemente o risco de desenvolver a doença severa, porém não souberam explicar a correlação da redução do risco de agravamento com o aleitamento materno.

Pacientes com diagnóstico positivo devem proceder com hidratação supervisionada, dieta leve e macia, higiene das mãos, pais e cuidadores devem evitar contato desnecessário com o paciente, não compartilhar os utensílios principalmente nos primeiros dias pela alta possibilidade de propagação do vírus ${ }^{2,3,24}$; assim como desinfecção das áreas comuns e brinquedos e afastamentos dessas crianças das creches e escolas ${ }^{2,4}$.

DISCUSSÃO

A doença mão-pé-boca é considerada
benigna, altamente contagiosa, indivíduos abaixo dos 10 anos, porém podendo afetar adultos também ${ }^{1-4}$, a maioria dos estudos consultados apontou como principais causadores os vírus Coxsackie A16 e o enterovírus 71, demais cepas como coxsackie A5, A7, A9, A10, B2, B5, ecovírus 9 também podem causar a doença. $\mathrm{O}$ enterovírus 71 constantemente relacionado às complicações neurológicas e cardiopulmonares ${ }^{10,12,16,22}$ porém, Fatahzadeh $^{3}$, em 2017, evidenciou que os surtos graves de doença envolvem o coxsakievirus A6.

Em 2010, Chatproedpai et al. ${ }^{18}$ detectaram que o enterovírus 71 foi o agente etiológico pedrominante nos casos da doença. Já Wu et al ${ }^{13}$ no mesmo ano, identificaram os vírus não-EV71 como os coxsackie A4, A6 A10 e A16 como prevalentes em relação ao enterovírus 71. Em 2017 Wang et al. ${ }^{14}$ demonstraram a predominância da circulação dos 
vírus associados à doença de 2009 a 2016, sendo o enterovírus 71 com destaque nos anos de 2009, 2011 e 2014 e o coxsackie A16 mais prevalente nos anos 2010, 2012 e 2016; nos anos 2013 e 2015 outros enterovírus, os quais não foram especificados no estudo, foram os mais abrangentes. E igualmente em 2017, He et al. ${ }^{15}$ apontaram a predominância do enterovírus 71 nos anos 2010, 2012, 2014; do coxsakie A6 em 2013 e 2015 e do coxsackie A16 em 2009; o que resultou em uma circulação dos vírus diferente do apresentado por Wang et al. ${ }^{14}$, mesmo sendo os dois estudos realizados na China e no mesmo ano, a variabilidade de agentes etiológicos detectados sugere que, apesar da proximidade entre os períodos e independendo da localização, os surtos da doença são restritos a patógenos específicos atuando muito provavelmente de forma independente.

Xing et al. $^{16}$ observaram que meninos, menores de 5 anos, tem mais tendência a desenvolver a doença do que meninas da mesma idade na proporção de 1,6 vezes a mais, que o surgimento ocorre nos meses mais quentes Chatproedai et al. ${ }^{18}$, em seu estudo com 48 casos da doença encontraram a prevalência da doença ocorrendo em crianças do gênero masculino com a idade média de 3 anos. Repass et al. ${ }^{10}$ relataram predominância em crianças abaixo dos 10 anos com maior incidência na primavera, verão e outono e sem predileção de gênero.

Alguns autores mencionaramm o calor excessivo como fator que favorece o aparecimento e evolução da doença em crianças na faixa etária de 3 a 6 anos de idade ${ }^{14,19}$, descrevendo a incidência da doença sob crianças menores de 5 anos, com a média de 2,4 anos e do gênero masculino. Koh et al. ${ }^{20}$, em revisão sistemática, verificaram que morar em área rural aumenta o riso de contrair a doença, que a mesma ocorrem em ambos os gêneros mas que os do masculino são mais propensos a ter sintomas e disseminar a doença, talvez por terem mais acesso aos tratamentos médicos do que os do gênero feminino e que não existe evidência sobre o período de incubação da doença. Dados de Pham et al. ${ }^{25}$, em estudo com 744 casos da doença, apontaram a maioria das crianças com menos de 3 anos e do sexo masculino.

A sintomatologia comumente descrita refere-se às lesões como máculas, vesículas ovais e dolorosas de 2 a $8 \mathrm{~mm}$ acizentadas com halo avermelhado nas palmas das mãos, planta dos pés, mucosa bucal, palato duro e língua ${ }^{2,22}$. Sendo que no meio bucal os locais de predileção das lesões são mucosa bucal, tonsilas, lábios e língua ${ }^{24}$. Dentre às manifestações sistêmicas são citadas a desidratação, meningite asséptica, paralisia focal aguda, encefalite, linhas de Beau, onicomadese e distúrbios cardiopulmonares ${ }^{4}$. Cepas do enterovirus, 71 são descritas como o principal agente causador da doença com manifestações mais severas que remetem à complicações no sistema nervoso central e problemas pulmonares acarretando cuidados médicos urgentes $^{22,25}$. Alguns autores ainda mencionam a leucocitose, mioclonia e úlceras na boca como achados relacionados aos casos severos da doença ${ }^{21}$.

O diagnóstico da doença usualmente é clínico, baseado na idade do paciente, tipologia dos sintomas e localização das lesões. Nas situações em que existe a hipótese de severidade, o padrão ouro para o diagnóstico definitivo é a cultura viral ${ }^{1,10,22}$. Este exame tipifica o enterovirus através do fluido da vesícula, fluido cérebro espinhal, sangue, biópsia, bolha, do esfregaço da garganta ou das fezes em casos incomuns da doença, para análise das espécies dos vírus ou em circunstâncias de pesquisa ${ }^{1,2,4,22}$. Conforme Fatahzadeh ${ }^{3}$ em 2017, os enfermos desenvolvem anticorpos que neutralizam o vírus coxsackie posteriormente a infecção por ele.

O quadro clínico da doença mão- pé-boca é semelhante às várias enfermidades viróticas da infância, podendo dessa forma ser confundido com outras doenças. O diagnóstico diferencial são as úlceras aftosas, herpangina, gengivoestomatite herpética, varicela, eritema multiforme, erupções medicamentosas, catapora, sarna, sarampo e herpes zoster. A gengivoestomatite herpética, assim como a doença da mão-pé-boca, afeta crianças menores e causa febre. $\mathrm{O}$ inchaço, inflamação e sangramento gengival, linfadenopatia cervical, vesículas e úlceras na boca e região perioral são características da gengivoestomatite herpética. Já a estomatite aftosa é identificada por úlceras maiores, dolorosa acometendo os lábios, língua e mucosa bucal, normalmente em crianças mais velhas e adultos, podendo ter várias etiologias. A sarna assemelha-se à doença mão-pé-boca pela presença de vesículas ou lesões nodulares nas mãos e nos pés e o que a diferencia é a intensa coceira interdigital. Em contraste com a doença mão-pé-boca, as lesões varicelares atinge uma área de pele maior, incluindo o couro cabeludo, sem as palmas das mãos e pés e as lesões formam crostas, enquanto as vesículas da doença mão-pé-boca cicatrizam pela reabsorção do líquido do interior da vesícula ${ }^{1,3,7,10,22.23}$. Fatahzadeh $^{3}$ descreve a herpangina como uma doença que ocorre em crianças pequenas, com febre, mal estar, e lesões orais principalmente no palato mole, úvula, parede posterior da faringe, tonsilas, originando dor e exsudato de garganta, odinofagia, disfagia. Segundo Repass et al. ${ }^{10}$ a herpangina é uma patologia muito semelhante à doença mão-pé-boca, porém sem manifestação na pele e é causada pelo Coxsackievírus A.

Até o presente momento, de acordo com a literatura consultada, não existe um tratamento específico para a doença mão-pé-boca. Os estudos 
mencionam que a mesma é autolimitada, com bom prognóstico. O tratamento clássico consiste em alívio da dor e prevenção, manter o paciente hidratado, alimentação líquida/pastosa, repouso, prescrição de analgésicos, antipiréticos, anti-inflamatórios, digluconato de clorexidina, gel de lidocaína à $2 \%$ para alívio dos sintomas, os quais de um modo geral melhoram em até 7 dias $^{2,3,9,27-29}$. Porém Cepeda ${ }^{6}$ discorda em relação ao uso de cremes e enxaguantes com substâncias anestésicas para alívio do desconforto na boca. A literatura também não aponta nenhuma terapêutica vacinal para doença, entretanto ressalta que os principais meios de prevenção consistem na higiene das mãos, dos utensílios, ingestão de água potável, aleitamento materno, distanciamento de pessoas contaminadas e afastamento do doente das escolas e creches $^{2,3,10,18,28,29}$.

A transmissão da doença é feco-oral, através de fluidos respiratórios, entre os familiares, da mãe para a criança, nas escolas, creches, brinquedotecas, acampamentos, orfanatos e pelos funcionários de hospital. A sobrevida do enterovirus em superfícies, na água, no esgoto e no solo úmido pode ocorrer por vários meses e nas fezes por até um mês ${ }^{1,9,15}$. Koh et al. ${ }^{20}$ destacam não haver evidências definidas sobre a transmissão da doença dentro das escolas e creches, mas enfatizam que o conhecimento sobre a transmissão é importante, pois, em muitos países, escolas são fechadas para evitar a propagação da doença entre as crianças.

CONCLUSÃO

$\mathrm{O}$ reconhecimento e identificação precoce das manifestações bucais das doenças virais por parte dos profissionais da odontologia é de extrema importância. A doença mão-pé-boca apresenta etiologia variada, porém com sinais e sintomas semelhantes a várias enfermidades que se manifestam nessa região. $\mathrm{O}$ diagnóstico normalmente é baseado no exame clínico, pois a confirmação etiológica é limitada aos casos severos ou em função de pesquisas. As complicações são raras, porém podem ocorrer e em determinadas circunstâncias levar ao óbito. Os surtos ocorrem geralmente na primavera, verão e outono. $\mathrm{O}$ tratamento é sintomático e preventivo.

É fundamental que o odontopediatra tenha o conhecimento sobre esta doença visto que pode ser o primeiro profissional a ter contato com a criança infectada. Na maioria das vezes as manifestações bucais precedem as erupções cutâneas, dependendo do momento em que esse paciente é examinado, apresentando aspectos clínicos variados, sendo assim este profissional deve estar apto para proporcionar um tratamento adequado, visando à diminuição do contágio entre indivíduos e evitando desta forma possíveis focos epidêmicos da doença.

\section{REFERÊNCIAS}

1. Sarkar PK, Sarker NK, Tayab A. Hand, foot and mouth disease (hfmd):an update. Bangladesh J Child Health. 2016;40(2):115-19.

2. Sarma N. Hand, foot, and mouth disease: current scenario and Indian perspective. Indian J Dermatol Venereol Leprol. 2013;79(2):165-75.

3. Fatahzadeh M. Oral manifestation of viral infections. Atlas Oral Maxillofac Surg Clin North Am. 2017;25(2):163-70.

4. Nassef C, Ziemer C, Morrell DS. Hand-foot-andmouth disease: a new look at a classic viral rash. Curr Opin Pediatr. 2015;27(4):486-91.

5. Grinde B, Olsen I. The role of viroses in oral disease. J Oral Microbiol. 2010;2(1):1-6.

6. Cepeda CO, Valverde AM, Recolons MMS, Salas EJ, Roig AM, López JL. A literature review and case reporto $\mathrm{f}$ hand, foot and mouth disease in na immunocompetent adult. BMC Res Notes. 2016;9:165.

7. Robinson CR, Doane FW, Rhodes AJ. Report of an outbreak of febrile illness with pharyngeal lesions and exanthem: Toronto, Summer 1957isolation of group A coxsackie virus. Can Med Assoc J. 1958;79(8):615-21.

8. Alsop J, Flewett TH, Foster JR. Hand-foot-andmouth disease" in Birmingham in 1959. Br Med J. 1960;2(5214):1708-11.

9. Cristovam MAS, Osaku NO, Gabriel GFCP, Rodrigues SPSG, Pompeu CB, Pires TG. Síndrome mão-pé-boca: relato de caso. Rev Med Res. 2014;16(1):42-5.

10. Repass GL, Palmer WC, Stancampiano FF. Hand, foot, and mouth disease: identifying and managing na acute viral syndrome. Cleve Clin J Med. 2014;81(9):537-43.

11. Kashyap RR, Kashyap RS. Hand, foot and mouth disease- a short case report. J Clin Exp Dent. 2015;7(2):e336-38.

12. Babu NA, Malathi L, Kasthuri M, Jimson S. Ulcerative lesions of the oral cavity - an overview. Biomed Pharmacol J. 2017;10(1):401-5.

13. Xing W, Liao Z, Sun J, Wu J T, Chang Z, Liu F, et al. Hand, foot, and mouth disease in China, 2008-12: an epidemiological study. Lancet Infect Dis. 2014;14:308-18.

14. Wu Y, Yeo A, Phoon MC, Tan EL, Poh CL, QuakSH et al. The largest outbreak of hand; foot and mouth disease in Singapore in 2008: the role of enterovirus 71 and coxsackievirus A strains. Int J Infect Dis. 2010;14:e1076-81.

15. Wang J, Hu T, Sun D, Ding S, Carr M, Xin W, et al. Epidemiological characteristics of hand, foot, and mouth disease in Shandong, China, 20092016. Sci Rep.2017;7(1):1-9.

16. He SZ, Chen MY, Xu XR, Yan Q, Niu JJ, Wu $\mathrm{WH}$ et al. Epidemics and aetiology of hand, foot 
and mouth disease in Xiamen, China, from 2008 to 2015. Epidemiol Infect. 2017; 145:1865-74.

17. Dantas A, Oliveira MJ, Lourenço O, Coelho PB. Doença mão-pé-boca no adulto - a propósito de um caso clínico. Rev Port Med Geral Farm. 2013;29:62-5.

18. Chatproedprai S, Theanboonlers A, Korkong S, Thongmee C, Wananukul S, Poovorawan. Clinical and molecular characterization of hand-foot-andmouth disease in thailand, 2008-2009. J Infect Dis. 2010;63:229-233.

19.Zhang W, Du Z, Zhang D, Yu S, Hao Y. Quantifying the adverse effect of excessive heat on children: an elevated risk of hand, foot and mouth disease in hot days. Sci Total Environ. 2016;541:194-99.

20. Koh WM, Bogich T, Siegel K, Jin J, Chong EY, Tan CY et al. The epidemiology of hand, foot and mouth disease in Asia: a systematic review and analysis. Pediatr Infect Dis J. 2016;35(10):e285-300.

21. Pham HV, Hoang TNA, Duong HT, Phan LT, Phan UTN, Ho NX et al. Clinical characteristics of hand, foot and mouth disease in Daklak Province, Vietnam and associated factors of severe cases. Virus Dis.2017;28(4):430-33.

22. Lam JM. Characterizing viral exanthems. Ped Health. 2010;4(6):623-35.

23. World Health Organization: western Pacific Region. A guide to clinical management and public health response for hand, foot, and mouth disease (HFMD).

24. Ganga N. Hand foot and mouth disease like illness in office practice. Indian J Pediatr. 2017; 84(3):216-18.

25. Chang LY, Lin TY, Hung K, Huang YC, Lin $\mathrm{KL}$, Hsueh $\mathrm{C}$ et al.Clinical features and risk factors of pulmonary oedema after en terovi rus71-related hand, foot, and mouth disease. Lancet. 1999;354(9191):1682-86.

26. Cabrol Y, Peah P, Mey C, Duong V, Richner B, Laurent $\mathrm{D}$ et al. A prospective, comparative study of severe neurological and uncomplicated hand, foot and mouth forms of paediatric enterovirus 71 infections. Int J Infect Dis. 2017;59:69-76.

27. Alter SJ, Bennett JS, Koranyi K, Kreppel A, Simon R. Common childhood viral infections. Curr Probl Pediatr Adolesc Health Care. 2015;45:21-53.

28. Li Y, Deng H, Li M, Wang W, Jia X, Gao N et al. Prolonged breastfeeding is associated with lower risk of severe hand, foot and mouth disease in chinese childre. Pediatr Infect Dis J. 2016;35(3):353-55.

29. Wolf D, Otto J. Efficacy and safety of lidocaine gel in patients from 6 months up 8 years with acute painful sites in the oral cavity: a randomized, placebo-contolled, double-blind, comparative study. Int J Pediatr. 2015.2015:146717.

\section{CONFLITO DE INTERESSES}

Os autores declaram não haver conflitos de interesse.

AUTOR PARA CORRESPONDENCIA

Ellen Cristina Gaetti Jardim

ellen.jardim@ufms.br

Submetido em 04/09/2019

Aceito em 29/11/2019 